University of Nebraska - Lincoln

DigitalCommons@University of Nebraska - Lincoln

Human Trafficking: Data and Documents

Interdisciplinary Conference on Human

Trafficking at the University of Nebraska

2002

\title{
Runaway/Thrownaway Children: National Estimates and Characteristics
}

Heather Hammer

Temple University Institute for Survey Research

David Finkelhor

University of New Hampshire

Andrea J. Sedlak

Westat, Inc.

Follow this and additional works at: https://digitalcommons.unl.edu/humtraffdata

Part of the Inequality and Stratification Commons

Hammer, Heather; Finkelhor, David; and Sedlak, Andrea J., "Runaway/Thrownaway Children: National Estimates and Characteristics" (2002). Human Trafficking: Data and Documents. 20.

https://digitalcommons.unl.edu/humtraffdata/20

This Article is brought to you for free and open access by the Interdisciplinary Conference on Human Trafficking at the University of Nebraska at DigitalCommons@University of Nebraska - Lincoln. It has been accepted for inclusion in Human Trafficking: Data and Documents by an authorized administrator of DigitalCommons@University of Nebraska Lincoln. 
J. Robert Flores

OJJDP Administrator

\section{Runaway/Thrownaway Children: National Estimates and Characteristics}

\author{
Heather Hammer, David Finkelhor, and \\ Andrea J. Sedlak
}

The words "missing child" call to mind tragic and frightening kidnappings reported in the national news. But a child can be missing for many reasons, and the problem of missing children is far more complex than the headlines suggest. Getting a clear picture of how many children become missing — and why —is an important step in addressing the problem. This series of Bulletins provides that clear picture by summarizing findings from the Second National Incidence Studies of Missing, Abducted, Runaway, and Thrownaway Children (NISMART-2). The series offers national estimates of missing children based on surveys of households, juvenile residential facilities, and law enforcement agencies. It also presents statistical profiles of these children, including their demographic characteristics and the circumstances of their disappearance.

This Bulletin provides information on the number and characteristics of children who are gone from their homes either because they have run away or because they have been thrown out by their caretakers. The estimates presented in this Bulletin are derived from three components of the Second National Incidence Studies of Missing, Abducted, Runaway, and Thrownaway Children (NISMART-2): the National Household Survey of Adult Caretakers, the National 


\section{Defining Runaways/Thrownaways}

A runaway episode is one that meets any one of the following criteria:

- A child leaves home without permission and stays away overnight.

- A child 14 years old or younger (or older and mentally incompetent) who is away from home chooses not to come home when expected to and stays away overnight.

- A child 15 years old or older who is away from home chooses not to come home and stays away two nights.

A thrownaway episode is one that meets either of the following criteria:

- A child is asked or told to leave home by a parent or other household adult, no adequate alternative care is arranged for the child by a household adult, and the child is out of the household overnight.

- A child who is away from home is prevented from returning home by a parent or other household adult, no adequate alternative care is arranged for the child by a household adult, and the child is out of the household overnight.

Household Survey of Youth, and the Juvenile Facilities Study. The NISMART-2 studies spanned the years 1997 to 1999.1 All data in the individual component studies were collected to reflect a 12 -month period. Because the vast majority of cases were from the studies conducted in 1999, the annual period being referred to in these Bulletins is 1999.

\section{Key Findings}

In 1999, an estimated 1,682,900 youth had a runaway/ thrownaway episode. Of these youth, 37 percent were missing from their caretakers and 21 percent were reported to authorities for purposes of locating them.

Of the total runaway/thrownaway youth, an estimated 1,190,900 (71 percent) could have been endangered during their runaway/thrownaway episode by virtue of factors such as substance dependency, use of hard drugs, sexual or physical abuse, presence in a place where criminal activity was occurring, or extremely young age (13 years old or younger).
Youth ages 15-17 made up two-thirds of the youth with runaway/thrownaway episodes during the study year.

- There is suggestive evidence that the runaway problem may have been smaller in 1999 than it was in 1988.

\section{Conceptualizing the Problem}

In the literature on missing children, runaways have sometimes been referred to as the "voluntary missing," to distinguish them from abducted and lost children. However, this term misstates the nature and complexity of the problem. It is generally recognized that children who leave home prematurely often do so as a result of intense family conflict or even physical, sexual, or psychological abuse. Children may leave to protect themselves or because they are no longer wanted in the home. The term "voluntary" does not properly apply to such situations.

To represent this complexity, NISMART-1, following the practice of many youth services agencies, employed the concept of thrownaway youth to characterize young people who were forced out of their homes or were refused permission to return (Finkelhor, Hotaling, and Sedlak, 1990). NISMART-1 presented separate estimates for the incidence of runaways and thrownaways. However, further analysis of NISMART-1 findings suggested that the distinction between runaways and thrownaways was less than clear cut. Many youth had both kinds of episodes, and many individual episodes had both runaway and thrownaway elements. Moreover, the categorization of an episode frequently depended entirely on whether information was gathered from the youth, who tended to emphasize the thrownaway aspects of the episode, or the caretakers, who emphasized the runaway aspects.

In consideration of these findings, NISMART-2 was structured to deemphasize the distinction between runaways and thrownaways and to count both as part of one larger group called runaway/thrownaway. The emphasis in NISMART-2 was to focus on the characteristics of episodes, whether runaway or thrownaway, that put youth at risk of harm. 
Runaway/thrownaway episodes can vary a great deal in their seriousness and dangerousness. The stereotype of the runaway is often of youth roaming and sleeping on the streets of a large city such as New York or San Francisco, prey to pimps, drug dealers, and violent crime. However, not all runaway/thrownaway youth are at such peril. At the other end of the continuum, some youth leave and go to the homes of friends and relatives, where they may be well cared for.

NISMART-1 characterized the seriousness of runaway/ thrownaway episodes according to whether the youth had a secure and familiar place to stay during the episode. However, the practice among those concerned about the well-being of runaways and thrownaways increasingly has moved to identify a longer and more specific list of factors that signify harm or risk for harm during such episodes. These factors include whether the youth were in the company of dangerous or predatory companions, whether they had serious mental health or substance abuse problems, whether they had been abused or had engaged in criminal activity during the episode, and whether they were extremely young (13 years old or younger). To identify these youth, NISMART-2 added a category, endangered children, whose runaway or thrownaway episodes involved any one of a list of 17 factors that placed them at risk for harm (see table 4, page 8).

A third complexity surrounding runaway/thrownaway youth is that, although they are gone from their households, not all of them are literally missing. Being missing implies that a youth's whereabouts are not known to his or her caretakers, who, as a result, are alarmed and try to locate the youth. However, sometimes when youth leave in runaway/thrownaway episodes, they go to the homes of friends or relatives or to shelters or social service agencies whose locations are well known to the caretakers. In other episodes, especially thrownaway episodes, children are not literally missing because their caretakers are not concerned about their whereabouts. Although these caretakers may not know where the youth are, they are not looking for them, are not alarmed, and might well be able to locate the youth easily if they decided to look for them.
Therefore, NISMART-2 distinguishes and presents separate counts of runaways/thrownaways in general and runaways/thrownaways who are missing. Moreover, two uses of the term "missing" are also differentiated:

Caretaker missing: NISMART-2 counts a child as missing from the caretaker's perspective when the child experienced a qualifying episode during which the child's whereabouts were unknown to the primary caretaker, with the result that the caretaker was alarmed for at least 1 hour and tried to locate the child.

Reported missing: A subset of caretaker missing, this category refers to youth whose caretakers have reported them to authorities in order to help locate them. Youth in this category are the missing youth for whom authorities, such as law enforcement agencies, are searching.

The diagram below illustrates the proportional relationships between all runaway/thrownaway children and the subsets who were caretaker missing and reported missing. It also shows that children who were reported missing are a subset of those who were caretaker missing. (Note that this Bulletin presents data on the characteristics of all runaway/thrownaway children, not just those who were caretaker missing or reported missing.)

Runaway/Thrownaway Children

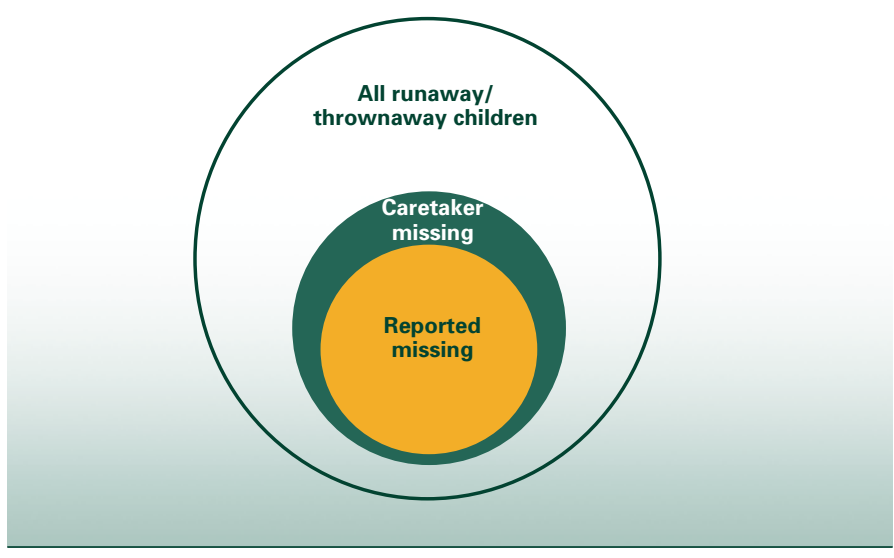

The diagram illustrates the proportions of children who were caretaker missing and reported missing in relation to all runaway/thrownaway children. 


\section{Methodology}

As noted earlier, the runaway/thrownaway estimates in this Bulletin are based on three components of the NISMART-2 studies: the National Household Survey of Adult Caretakers, the National Household Survey of Youth, and the Juvenile Facilities Study.

\section{The National Household Surveys}

The National Household Survey of Adult Caretakers and the National Household Survey of Youth were conducted during 1999. Both surveys used computer-assisted telephone interviewing methodology to collect information from a national probability sample of households. A total of 16,111 interviews were completed with an adult primary caretaker, resulting in an 80-percent cooperation rate among eligible households with children and a 61percent response rate. Each primary caretaker who completed an interview was asked for permission to interview one randomly selected youth in the household ages 10-18. Permission was granted to interview 60 percent of the selected youth, yielding 5,015 youth interviews and a 95-percent response rate for the youth for whom permission was granted.

A set of 17 screening questions was used to determine the eligibility of both the adult caretakers and youth for an indepth followup interview designed to collect detailed information about each type of episode reported in the screening interview. Responses to the following seven episode screening questions steered an adult respondent into a runaway/thrownaway followup interview:2

In the last year, did [this child/any of these children] leave home without permission and stay away for at least a few hours?

- Did [this child/any of these children] stay away for at least one night?

- Did [this child/any of these children] choose not to come home from somewhere when [he/she/they] [was/were] supposed to, and stay away for at least two nights?

Did you or any adult member of your household force or tell [this child/any of these children] to leave home, or decide not to allow [him/her/them] back in the home?
Did [this child/any of these children] leave for at least one night?

- Was there any time when having [this child/any of these children] in your home became a lot of trouble and [he/she/they] left?

- Other than anything you have already told me about, has there been any time, either currently or during the past 12 months, when you did not know where [this child/any of these children] [was/were] living?

The total number of children included in the adult Household Survey sample was 31,787 . The total number of youth included in the youth Household Survey sample was 5,015. The adult and youth Household Survey data were weighted to reflect the U.S. Census-based population of children. ${ }^{3}$

One obvious limitation to the Household Surveys is that they may have undercounted children who experienced episodes but were living in households without telephones or were not living in households during the study period, including street children and homeless families. Although these are not large populations, they may be at risk for episodes.

There is an additional group of children who should be included in the runaway/thrownaway category, but who may not have been well counted by the Household Surveys or Juvenile Facilities Study: permanently abandoned children. Because of the stigma attached to abandonment, it is unlikely that caretakers would disclose such children to interviewers. A special analysis of data from the Third National Incidence Study of Child Abuse and Neglect (NIS-3), obtained through a different methodology, estimated the approximate size of this group to be $56,900.4$

\section{The Juvenile Facilities Study}

Although the majority of runaway/thrownaway children were expected to be living in households at the time of the episode, a considerable number of youth also run away from facilities such as group homes and youth detention centers where they may be living. Therefore, NISMART-2 conducted a national survey of facilities where juveniles reside to obtain information on runaways/thrownaways from such facilities. The information obtained from the Juvenile Facilities Study enabled NISMART-2 to avoid 
double-counting youth who ran away from both a household and a juvenile facility in the course of the study year.

The respondents in the Juvenile Facilities Study were staff from a nationally representative sample of 74 facilities, including juvenile detention centers, group homes, residential treatment centers, and shelters for runaway and homeless youth. The study used a stratified, two-stage sample. In the first stage, 33 counties were sampled from the universe of U.S. counties. In the second stage, juvenile facilities were sampled within the selected counties. 5

Respondents at each of the selected facilities were contacted by telephone and interviewed to determine the number of children who ran away from each facility in 1997, and details were obtained about the five most recent runaway episodes. All of the selected facilities that were operational participated in the study, providing facilitylevel information and yielding a 93-percent response rate for the targeted episode-level interviews. The Juvenile Facilities Study runaways were assigned weights to reflect the probability of having included the facility and episode in the sample and to adjust for nonresponse.

\section{Unified Estimates}

The runaway/thrownaway estimates reported in this Bulletin are unified estimates that combine the numbers of countable runaway/thrownaway children reported in each of the component studies discussed above. Any single child was allowed to count in the unified estimate only once, even if a countable runaway/thrownaway episode was reported for the same child in both the adult and youth interviews, or the child ran away from both a household and a facility in the study year. A detailed description of the unified estimate methodology is provided in OJJDP's forthcoming Unified Estimate Methodology Technical Report.
All estimates in the results reported below have been rounded to the nearest 100 . As a result of the rounding, the percentages may not sum to 100 .

\section{Results}

The number of U.S. youth estimated to have had a runaway/thrownaway episode in 1999 is $1,682,900$ (see table 1). Of these, an estimated 628,900 , or 37 percent, were "caretaker missing" youth. Only an estimated 357,600 youth, or 21 percent of all runaways/thrownaways, were reported missing to police or to a missing children's agency for purposes of locating them. (See diagram on page 3.) Based on 17 indicators of harm or potential risk, 1,190,900 of the runaway/thrownaway youth (71 percent) were estimated to be endangered.

The NIS-3 data were used to get a sense of the number of permanently abandoned children, who probably were not well counted in the NISMART-2 surveys. An estimated 56,900 children were permanently abandoned in 1993, the last year that the NIS was conducted. These children are not included in subsequent tables and discussions in this Bulletin. Had the analyses included these children, the study findings would not have been substantively altered, since abandoned children would have comprised an extremely small portion ( 3 percent) of all runaways/thrownaways. 6 
Table 2: Characteristics of Runaways/Thrownaways

\begin{tabular}{lrcc} 
Characteristic & Estimate & $\begin{array}{c}\text { Percent } \\
(\boldsymbol{n}=\mathbf{1 , 6 8 2 , 9 0 0 )}\end{array}$ & $\begin{array}{c}\text { Percent of U.S. } \\
\text { Child Population } \\
\text { Ages 7-17* }\end{array}$ \\
\hline (N= 43,372,500)
\end{tabular}

Note: Because all estimates have been rounded to the nearest 100, percentages may not sum to 100.

* Age, gender, and race for the U.S. population were based on the average monthly estimates of the population ages 7-17 years for 1999 (U.S. Census Bureau, 2000).

t Estimate is based on too few sample cases to be reliable.

of runaways/thrownaways traveled a distance of 50 miles or more from home, and 9 percent left the State in the course of an episode. Most runaway/thrownaway youth were gone less than 1 week (77 percent), and only 7 percent were away more than 1 month.

Nearly all of the runaway/thrownaway children $(1,676,200$ or 99.6 percent $)$ had returned home by the time the study data were collected. Only a fraction of a percent $(6,300$, or less than 0.4 percent $)$ had not returned home. 7

Table 4 lists the 17 features of runaway/ thrownaway episodes deemed to be indicators of endangerment. Any youth who qualified under any one of these conditions was classified as an endangered runaway/thrownaway. The most common endangerment component was physical or sexual abuse at home or fear of abuse upon return. The second most common endangerment component was substance dependency. Substantial numbers of children were also endangered by virtue of their young age (13 years old or younger), being in the company of some-

Most runaway/thrownaway youth (68 percent) were older teens, ages 15-17 (table 2). At these ages, youth are often more independent, tend to resist parental authority, are more likely to become involved in activities that bring them into conflict with their caretakers, and are often viewed by their caretakers as being capable of living on their own. All these things may increase the likelihood of runaway/thrownaway episodes. Nonetheless, a small group of children younger than age 12 did experience such episodes. Runaway/thrownaway youth were equally divided between boys and girls and did not come disproportionately from any of the major racial and ethnic groups.

A somewhat larger number of runaway/thrownaway episodes occurred during summer, a time when young people are more mobile and less constrained by weather and school activities (table 3). Approximately 23 percent one known to be abusing drugs, or use of hard drugs by the children themselves. An estimated 38,600 runaways/ thrownaways ${ }^{8}$ were at risk of sexual endangerment or exploitation by one or more of the following characteristics or behaviors during the episode: the youth was sexually assaulted, there was an attempted sexual assault of the youth, the youth was in the company of someone known to be sexually abusive, or the youth engaged in sexual activity in exchange for money, drugs, food, or shelter during the episode.

Police were contacted in regard to a little less than onethird of the runaway/thrownaway youth (table 5). The most common reason for police contact was to help locate missing youth. However, police were also involved for other reasons, such as the youth being picked up for suspicious or criminal activity. 9 When police were not contacted, two prominent reasons given were that 
NISMART

the caretakers knew the child's location or simply did not think the police were needed.

To look for historical trends, a special analysis of NISMART-2 data was conducted using the closest possible approximation of NISMART-1 definitions and methodology. 10 The estimates for the more serious category of runaways (runaways, not thrownaways, who lacked a secure and familiar place to stay) were lower in 1999 than in 1988. The difference approached significance at $p=.06$ (two-tailed test), which is probably, but not conclusively, a large enough margin of error to believe that an actual decline had occurred.

\section{Implications}

The estimated number of runaway/thrownaway children in NISMART-2, nearly 1.7 million, is large both in absolute terms and in relation to previous estimates of the size of the problem, including those from NISMART-1. The large number in the present study is a result of a methodology not previously used in research on this problem: NISMART-2 interviewed a national sample of caretakers and a national sample of youth and combined both to arrive at a unified estimate.

Because the NISMART-2 estimates are larger than the NISMART-1 estimates and those produced by other previous studies, it is possible to conclude, mistakenly, that the size of the problem has increased over time. In fact, an explicit comparison between NISMART-1 and NISMART-2 suggests that the problem may have declined. The bigger estimates from NISMART-2 are primarily the result of interviewing, for the first time, youth themselves about their own experiences. These results clearly indicate that future efforts to count and characterize the nature of runaway/ thrownaway episodes should include a youth interview component.
Table 3: Characteristics of Runaway/Thrownaway Episodes

\begin{tabular}{|c|c|c|}
\hline Characteristic of Episode & $\begin{array}{c}\text { Estimated } \\
\text { Number of } \\
\text { Children }\end{array}$ & $\begin{array}{c}\text { Percent } \\
(n=1,682,900)\end{array}$ \\
\hline \multicolumn{3}{|l|}{ Season } \\
\hline Winter & 335,400 & 20 \\
\hline Spring & 333,600 & 20 \\
\hline Summer & 655,100 & 39 \\
\hline Fall & 343,300 & 20 \\
\hline No information & $15,600 *$ & $<1^{*}$ \\
\hline \multicolumn{3}{|l|}{ Number of miles traveled from home } \\
\hline 1 or less & 139,900 & 8 \\
\hline More than 1 but no more than 10 & 503,100 & 30 \\
\hline More than 10 but no more than 50 & 521,900 & 31 \\
\hline More than 50 but no more than 100 & 160,100 & 10 \\
\hline More than 100 & 210,600 & 13 \\
\hline No information & 147,300 & 9 \\
\hline \multicolumn{3}{|l|}{ Child left the State } \\
\hline Yes & 147,600 & 9 \\
\hline No & $1,393,000$ & 83 \\
\hline No information & 142,300 & 8 \\
\hline \multicolumn{3}{|l|}{ Duration } \\
\hline 6 to less than 7 hours & $21,000 *$ & $1 *$ \\
\hline 7 hours to less than 24 hours & 307,400 & 18 \\
\hline 24 hours to less than 1 week & 975,700 & 58 \\
\hline 1 week to less than 1 month & 248,000 & 15 \\
\hline 1 month to less than 6 months & 123,000 & 7 \\
\hline Not returned, but located & $2,200^{*}$ & $<1^{*}$ \\
\hline Not returned and not located & $4,100 *$ & $<1^{*}$ \\
\hline No information & $1,600^{*}$ & $<1^{*}$ \\
\hline \multicolumn{3}{|l|}{ Episode Outcome } \\
\hline Child returned & $1,676,200$ & $>99$ \\
\hline Child not returned, but located & $2,200^{*}$ & $<1^{*}$ \\
\hline Child not returned and not located & $4,100^{*}$ & $<1^{*}$ \\
\hline No information & $400 *$ & $<1^{*}$ \\
\hline
\end{tabular}

Note: Because all estimates have been rounded to the nearest 100, percentages may not sum to 100

* Estimate is based on too few sample cases to be reliable. 
Table 4: Estimates of Potentially Endlangered Runaways/Thrownaways

Characteristic of Episode

to the episode or was afraid of abuse upon return

Child was substance dependent

Child was 13 years old or younger

Child was in the company of someone known to be abusing drugs

Child was using hard drugs

Child spent time in a place where criminal activity was known to occur

Child engaged in criminal activity during the course of the episode

Child was with a violent person

Child had previously attempted suicide

Child who was enrolled in school at the time of the episode missed at least 5 days of school

Child was physically assaulted or someone attempted to physically assault child during the course of the episode

Child was with a sexually exploitative person

Child had a serious mental illness or developmental disability at the time of the episode

Child was sexually assaulted or someone attempted to sexually assault child during the course of the episode

Child's whereabouts were unknown to the caretaker for at least 30 days (and the episode was unresolved or no information was available)

Child engaged in sexual activity in exchange for money, drugs, food, or shelter during the episode

Child had or developed a serious or life-threatening medical condition during the course of the episode
Percent

$(n=1,682,900)$

Estimate

21

19

18

18

17

12

256,900

11

97,400

125,400

70,500

7

4

70,500

4

69,100

4

$27,300^{*}$

2*

$24,300 *$

1 *

$14,900 *$

$1 *$

$7,300 * \quad<1$ *

$1,700^{*} \quad<1^{*}$

$0^{+}$

$0^{\dagger}$

Note: The total number of endangered runaway/thrownaway youth was 1,190,900. The individual estimates and percents do not sum to the total because the youth were counted in each category that applied. For this reason, the numbers and percentages cannot be combined to create aggregates.

* Estimate based on too few sample cases to be reliable.

† No cases were identified.

The inclusion of the youth sample dramatically increased the estimate arrived at by simply relying on information obtained from caretakers. This is probably because youth were willing to disclose episodes, particularly thrownaway episodes, that caretakers may have been reluctant to report. Moreover, the runaway/thrownaway episodes are more salient for the youth, thereby making it more likely that they remember and report such episodes. However, the possibility cannot be excluded that youth, whether seeking to appear adventuresome or nurturing grievances against their caretakers, may have exaggerated the characteristics of episodes that may not have qualified as full-blown runaway/thrownaway incidents from an independent perspective.

The new information on endangered runaways/ thrownaways provides a picture of a large number of youth suffering from drug problems and physical or sexual abuse in addition to their episodes. Alarming numbers of runaways/thrownaways are in the company of violent, sexually exploiting, or drug-abusing compan- 
ions or suffer an actual or attempted assault while away from home. These are clearly among the subgroups of runaways/thrownaways in greatest need of assistance-assistance that goes far beyond simply locating their whereabouts and returning them to their homes. In fact, for some youth, such as the physically and sexually abused, being returned to their homes may increase rather than alleviate their danger. For this reason, any law enforcement response to runaway/thrownaway youth should be accompanied by a strong social service and mental health component that can attend to the child maltreatment, family conflict, substance abuse, and traumatic stress that precipitate and complicate these episodes.

At the same time, the findings from NISMART-2 confirm and emphasize the diversity of runaway/ thrownaway experiences. Many of the episodes were very brief. Most of the youth remained close to their homes. In a substantial number of episodes, the caretakers knew the child's location, and most of the caretakers did not see the episode as serious enough to warrant police contact.

The relatively low number of runaway/thrownaway youth for whom there was police contact may prompt some policymakers and practitioners to urge more police reporting. However, no conclusion can be drawn from the NISMART-2 data about whether families and children would benefit from greater, or even possibly less, police involvement in runaway/ thrownaway episodes. Caretakers may, in fact, be making appropriate judgments about when to turn to the authorities. Separate studies that evaluate the costs and benefits of police involvement are needed to answer this public policy question.

Runaways/thrownaways constitute the largest component of children reported missing to authorities. They make up almost half ( 45 percent) of all children reported missing and greatly dwarf the numbers who are reported missing because of family or nonfamily abduction or who are lost or injured. (The other large segment of children reported missing-sometimes confused with runaways/thrownaways-are the 43 percent who are reported missing for benign reasons, such as miscommunications between family members about who
Table 5: Police Contact for Runaways/Thrownaways

\begin{tabular}{|c|c|c|}
\hline Characteristic & Estimate & Percent \\
\hline \multicolumn{3}{|l|}{ Police contact* } \\
\hline Yes & 539,100 & 32 \\
\hline No & $1,143,800$ & 68 \\
\hline Total & $1,682,900$ & 100 \\
\hline \multicolumn{3}{|l|}{ Reason for police contact } \\
\hline Locate missing child & 158,000 & 29 \\
\hline $\begin{array}{l}\text { Recover child from known } \\
\text { location }\end{array}$ & $25,000 *$ & $5 *$ \\
\hline Other reason & 49,100 & 9 \\
\hline No information & 307,000 & 57 \\
\hline Total & 539,100 & 100 \\
\hline \multicolumn{3}{|l|}{$\begin{array}{l}\text { Reason police were not } \\
\text { contacted }\end{array}$} \\
\hline Knew child's location & 243,900 & 21 \\
\hline Did not think police were needed & 208,500 & 18 \\
\hline Child was not gone long enough & 95,800 & 8 \\
\hline Expected child to return & 80,500 & 7 \\
\hline $\begin{array}{l}\text { Did not want to get child in } \\
\text { trouble or arrested }\end{array}$ & $41,300^{+}$ & $4^{+}$ \\
\hline Believed child was safe & $17,000^{\dagger}$ & $1^{\dagger}$ \\
\hline $\begin{array}{l}\text { Caretakers did not care } \\
\text { that child was gone }\end{array}$ & $14,800^{+}$ & $1^{\dagger}$ \\
\hline $\begin{array}{l}\text { Because of prior runaway } \\
\text { experience }\end{array}$ & $10,800^{+}$ & $1+$ \\
\hline Other reason & 110,700 & 10 \\
\hline No information & 333,700 & 29 \\
\hline Total & $1,143,800$ & 100 \\
\hline
\end{tabular}

* Unified estimate derived from responses to the National Household Survey of Adult Caretakers, the National Household Survey of Youth, and the Juvenile Facilities Study.

† Estimate is based on too few sample cases to be reliable.

was to be where at what time.) Moreover, NISMART-2 demonstrates that there are hundreds of thousands more runaways/thrownaways who have not been, but potentially could be, reported to the police. Any thorough reconsideration of societal responses to the problem of missing children needs to give central attention to the law enforcement response to runaways/thrownaways. 


\section{Endnotes}

1. The reference dates for some of the NISMART-2 component studies vary because of a delay caused by pending Federal legislation that, had it passed, would have made it impossible to conduct the National Household Survey of Youth, a key component of NISMART-2. In anticipation of a quick resolution, OJJDP decided to proceed with the Law Enforcement Study and the Juvenile Facilities Study because neither involved interviewing youth. Had these 1997 studies been postponed until 1999, it is highly unlikely that those estimates would have been statistically different.

2. Respondents were instructed that these questions applied only to their child or children 7 years of age or older. A parallel set of episode screening questions were asked of the 10- to 18-year-old youth interviewees.

3 . For details about the weighting procedure and variance estimation, see OJJDP's forthcoming NISMART-2 Household Survey Methodology Technical Report.

4. The NIS-3 data were collected in 1993 from a sample of 5,612 professionals in a nationally representative sample of 42 counties who were charged with being on the lookout for maltreated children during a 3-month study period. The child protective services agencies in the same counties also provided data on maltreated children to the study. Duplicate records on the same child were eliminated, standard definitions of abuse and neglect were applied to all cases, and the data were weighted and annualized to provide estimates of the numbers of maltreated children in the United States in the study year. Details are given in Sedlak and Broadhurst (1996).

5. For details about the methodology used in the Juvenile Facilities Study, see OJJDP's forthcoming Juvenile Facilities Study Technical Report.

6. A number of considerations argued against integrating these children into the NISMART runaway/thrownaway estimates. First, NIS-3 and NISMART were conducted at different points in time (1993 vs. 1999). Second, it was not possible to assure that children counted in NIS-3 had not also been counted in one of the NISMART-2 surveys-a necessary assumption for integrating the NIS-3 and NISMART data into a unified estimate (see
OJJDP's forthcoming Unified Estimate Methodology Technical Report). Finally, the NIS-3 study cases were missing information about a number of characteristics, so even if the timeframe and unification issues could be resolved, the NIS-3 data would not have contributed to the case profiles given here.

7. A substantial number of runaways/thrownaways who had not returned (an estimated 2,500) were runaways from institutions who had been identified through the Juvenile Facilities Study. While individual facilities report their runaways to the authorities legally responsible for the youth (e.g., child welfare, juvenile justice, mental health), it sometimes happens that these authorities place a recovered child in another facility without notifying the original facility.

8. This estimate was carefully developed to count each youth only once. Because some youth had more than one of the characteristics listed in table 4, the estimates for these separate characteristics should not be summed.

9. For this reason, the number of police contacts was greater than the number of youth in the reported missing category, which was estimated as 357,600 , or 21 percent.

10. The results of this analysis will be presented in OJJDP's forthcoming Bulletin, Historical Change in the Incidence of Missing, Abducted, Runaway, and Thrownaway Children, 1988-1999. Note that NISMART-1 and NISMART-2 data and findings should not be compared directly because of differences in both definitions and methodology. The NISMART-2 definition of runaways/ thrownaways combines the individual runaway and thrownaway categories used in NISMART-1. In addition, in NISMART-2, runaway/thrownaway episodes were identified not simply through interviews with caretakers but also through interviews with juveniles.

\section{References}

Finkelhor, D., Hotaling, G., and Sedlak, A. 1990. Missing, Abducted, Runaway, and Thrownaway Children in America. First Report: Numbers and Characteristics National Incidence Studies. Washington, DC: U.S. Department of Justice, Office of Justice Programs, Office of Juvenile Justice and Delinquency Prevention. 
Sedlak, A.J., and Broadhurst, D.D. 1996. Third National Incidence Study of Child Abuse and Neglect: Final Report. Washington, DC: U.S. Department of Health and Human Services.

U.S. Census Bureau. 2000. Monthly Postcensal Resident Population, by Single Year of Age, Sex, Race, and Hispanic Origin (e9899rmp.txt, e9999rmp.txt, and e9900rmp.txt). Web site: eire.census.gov/popest/ archives/national/nat_90s_detail/nat_90s_1.php.
This Bulletin was prepared under grant number 95-MC-CX-K004 from the Office of Juvenile Justice and Delinquency Prevention, U.S. Department of Justice, to Temple University.

The Office of Juvenile Justice and Delinquency Prevention is a component of the Office of Justice Programs, which also includes the Bureau of Justice Assistance, the Bureau of Justice Statistics, the National Institute of Justice, and the Office for Victims of Crime.

\section{Acknowledgments}

Heather Hammer, Ph.D., is a Senior Study Director at the Temple University Institute for Survey Research, Philadelphia, PA, and Principal Investigator of NISMART-2. David Finkelhor, Ph.D., is Professor of Sociology and Director of the Crimes against Children Research Center, University of New Hampshire, and Advisor to NISMART-2. Andrea J. Sedlak, Ph.D., is Associate Director of Human Services Research at Westat, Inc.; Project Director of the NISMART-2 Unified Estimate, Juvenile Facilities Study, and Law Enforcement Study; and Advisor to the NISMART-2 Household Survey.

Other contributors include Louise Hanson, M.A.S., Senior Study Director at the Temple University Institute for Survey Research and Director of Data Collection for the NISMART-2 Household Surveys; Cassandra C. Gibson, Ph.D., LCSW-C, Study Director at the Temple University Institute for Survey Research; Michael K. Barr, M.A., Associate Study Director at the Temple University Institute for Survey Research; Dana J. Schultz, M.P.P., Policy Analyst at Westat, Inc., Operations Manager of the Juvenile Facilities Study and Law Enforcement Study, and Analyst for the Unified Estimate; Richard Ormrod, Ph.D., Research Professor of Geography at the University of New Hampshire Crimes against Children Research Center; G. Hussain Choudhry, Ph.D., Senior Statistician at Westat, Inc.; Svetlana Ryaboy, Statistician at Westat, Inc.; Monica Basena, Analyst at Westat, Inc.; and Ying Long, Programmer at Westat, Inc.

The authors extend their appreciation to Barbara Allen-Hagen, Senior Social Analyst at OJJDP and NISMART-2 Program Manager, for her support and guidance in every phase of this project. The authors also thank the many individuals who responded to the NISMART-2 surveys for their cooperation and candor. 
Washington, DC 20531

Official Business

Penalty for Private Use $\$ 300$

\section{For Further Information}

NISMART Questions and Answers, a fact sheet, offers a straightforward introduction to NISMART-2. It answers anticipated questions-such as What is NISMART? Have abductions by strangers declined or increased? and Why can't I compare NISMART-1 statistics with NISMART-2 statistics? - to help explain NISMART's purpose, methodology, and findings.

The first Bulletin in the NISMART series, National Estimates of Missing Children: An Overview, describes the NISMART-2 component studies and estimating methodology, defines the types of episodes studied-nonfamily abduction (including stereotypical kidnapping); family abduction; runaway/thrownaway; missing involuntary, lost, or injured; and missing benign explanation-and summarizes NISMART-2 estimates of missing children.

AII NISMART-related publications are available at OJJDP's Web site, ojjdp.ncjrs.org.

\section{Take}

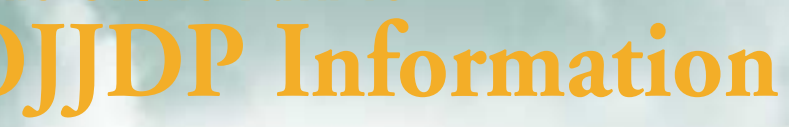

W ant to know more about the issues in this Bulletin or related information? Log on to ojjdp.ncjrs.org:

Browse titles alphabetically or by topic.

- Discover the latest OJJDP releases.

- Subscribe to OJJDP's listserv JUVJUST and the electronic newsletter JUSTINFO.

- Link to the NCJRS Abstracts Database to search for publications of interest.

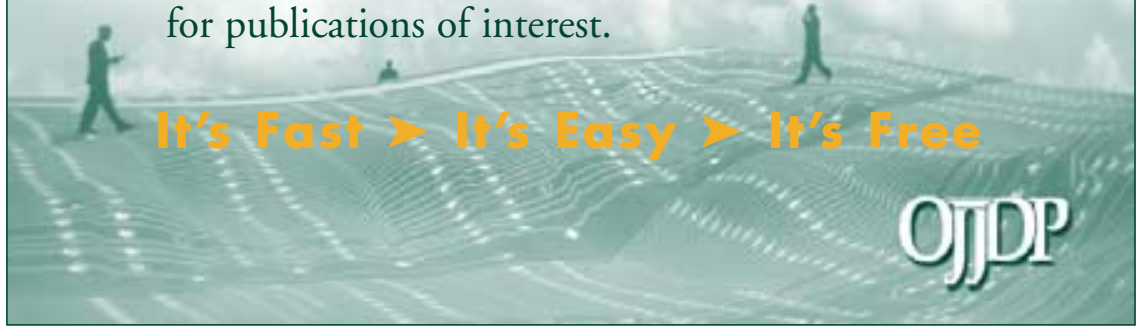

